\title{
Avoiding gender bias during measurement of individual research output of scientists - adaption of an analytical concept developed for health care research
}

\author{
Ulla Große, Martina Brandt
}

\section{Zusammenfassung}

Das im 7. Forschungsrahmenprogramm geförderte Projekt »Academic Careers Understood through Measurement and Norms« (ACUMEN) zielt auf die Aufhebung der Diskrepanz zwischen den breiter gewordenen sozialen und wirtschaftlichen Funktionen von Forschung und Lehre in allen Wissenschaftsbereichen und den gegenwärtig genutzten Kriterien für die karriererelevante Leistungsbewertung von Forschern. Um die Geschlechterdimension bei den sehr unterschiedlichen Forschungsaktivitäten aller Arbeitspakete des Projekts zu berücksichtigen, wurde ein methodologisch orientiertes Konzept, welches systematisch für die Gesundheitsforschung entwickelt wurde, in zwei Schritten auf den Forschungsgegenstand »Messung des individuellen wissenschaftlichen Outputs« übertragen. Der vorliegende Artikel fasst die wesentlichen - als relevant identifizierten und angepassten - Leitlinien zusammen. Diese werden mit Bezug auf Forschungskonzept, Forschungsdesign/-fragen, Methoden und Datenerfassung, Datenanalyse und Interpretation sowie Titel, Abstract, Diktion und Ergebnis-Visualisierung als wesentliche Schritte der Projektbearbeitung dargestellt. Unter Nutzung dieser Leitlinien des adaptierten Konzepts werden für die in ACUMEN geplanten Befragungen und Interviews modellhaft Fragen formuliert.

\section{Abstract}

For the Framework Research Program 7 funded project »Academic Careers Understood through Measurement and Norms (ACUMEN), addressing the current discrepancy between the broader social and economic functions of scientific and scholarly research in all fields of the sciences, social sciences and the humanities and the dominant criteria for evaluating performance by researchers, it was necessary to have a concept what allowed to substantiate the gender dimension during the different research activities. The present paper shows the steps adapting a methodological oriented concept, developed systematically for health care studies to the other subject. It summarizes some points identified as possibly relevant and adapted especially for surveys and the qualitative interviews to know more about measuring of scientific output of scientists. The deduced procedures and advices are structured with regard to the research concept, the research design/questions, the methods and data collection, the data analysis and interpretation just like title, abstract, diction and visualization of reports as several research project steps. By using the adapted concept were deduced model questions for surveys and interviews, which are planned by ACUMEN partners.

\section{Introduction}

More and more scientific based studies for policy and international organizations have to substantiate the dimension of gender. In contrast to the biological sex, referring to biological differences, gender describes the characteristics of the social construct that the society or culture attribute to women and to men. The gender dimension has to be taken into account particularly in the questions of presence, distribution of tasks, access to resources (like time, money, mobility), exclusion, rules and values, also examples and overall concepts (Baer 2003).

If the gender dimension is missed, a gender bias may occur and affect negatively the data, interpretation and results of studies. This, of course, leads to risks in conclusions and decisions based on these research results. That is why knowledge about methods to avoid a gender bias is important. Bias avoiding methods are more and more one benchmark of quality in scientific research. 
But how to substantiate the gender dimension during research activities? This was the question in the Framework Research Program 7 funded project »Academic Careers Understood through Measurement and Norms«. It addresses the current discrepancy between the broader social and economic functions of scientific and scholarly research in all fields of the sciences, social sciences and the humanities and the dominant criteria for evaluating performance by researchers (ACUMEN 2011).

In nearly all ACUMEN research questions of understanding processes of measuring and evaluating researchers performance and its impacts of careers of scientists the dimension of gender plays an important role. That's why it is important to find out detailed information about male and female scientists with all used and verified methods (webometric, bibliometric, peer review, ...) and to have conceptual assistance for all members of the European research collaboration, to do this. To give some conceptual assistance to all project partners one of the ACUMEN work packages deals with gender effects of evaluation specifically. The task was to find out gender bias identifying and avoiding procedures during the whole research process.

\section{Findings from literature - dimensions of a gendered view}

A literature search verified that there are a lot of findings about the representation of women and men in different research disciplines and career levels. These findings show the so called "gender gap «, in some cases named as »gender bias«, too. There are identified multiple reasons of this gender inequalities (overview: European Commission 2009) and several theories about factor combinations (e. g. Risberg et al. 2009; Abbuhl et al. 2010; Duberley/Cohen 2010; Elg/Jonnergard 2010; Winslow 2010; Morahan et al. 2011) just like concepts and tested models to overcome this unsatisfactory situation (e. g. Girves et al. 2005; Rose 2005; Bakken et al. 2006; Morrissey/Schmidt 2008; Mayer et al. 2010; Bird 2011).

It became clear, that a "gendered view « in research processes has at least two dimensions: To identify gender gaps in real proportions of women and men in the scientific world today and to avoid »self-produced « distortions in findings and conclusions.

As also in the scientific literature with regard to aca- demic careers the terms "gender gap « and "gender bias« are used in very varied contexts and in a badly unspecific manner and because there are not usable conceptual models for practicing the gendered view within different research designs for measuring scientific output on individual level it was necessary to find a concept with methodological focus for use in the ACUMEN project.

\section{Gender bias concept in health care studies as starting point}

This concept was found in the field of Health care studies. For this research area Eichler and colleagues within some years developed an analytical concept of identifying gender bias and achieving gender bias free research results. (Fuchs et al. 2002) In the present paper we try to adapt this concept to the ACUMEN research subject, especially for the instruments of survey and qualitative interviews.

In the understanding by Eichler gender bias is a gender-linked bias effect of research results. Due to conceptual or methodical incorrectness may result distortion effects in gender aspects and lead to results differing from the reality.

Mainly based on works of Margrit Eichler (Eichler at al. 1999) three dimensions of gender bias are known. The first two dimensions were developed with reference to Ruiz (Ruiz/Verbrugge 1997). These three bias dimensions can occur simultaneously or singly and can be shortly described as follow:

- Overgeneralization

(means the adoption of the experience or perspective of only one sex and applying it to both sexes, e. $g$. androcentrism, where the men are the norm, against which women are measured. It is important to state that gender bias may induce disadvantage not only for women, but also for men [1].)

- Gender insensitivity or gender blindness

(e. g. decontextualism/ignorance of biological sex or social gender, assumption of equality of women and men)

- Double standards in evaluation (open and concealed; similar or identical characteristics or behaviors of women and men are evaluated or investigated in different ways - genders are treated as two completely separate groups without any common features or use of gender stereotypes)

The quality of research data without a gender bias can 
reach different levels - from »sex counting « as the lowest level up to »gender competent data «. In the first case disaggregated data for women and men are collected and reported. It is important to state that the gender bias is one of several possible biases which can also arise with regard to age, disability, religion, ethnicity and so on (e. g. Eichler/Burke 2006). So the highest quality level results from additionally checking the influence of other characteristics as gender on the measured data, mostly gained by combining results of several studies.

\section{Adaption to the ACUMEN research subject »individual research output of scientists«}

For the necessary adaption of the concept was used an two step approach. For each of the steps occurring in scientific studies - from planning up to reporting - firstly was done an at most theoretical generalization of the health care focused advices. Secondly was assessed the level of gender bias absence in the ACUMEN thinking at the whole and in the concepts of the different work packages.

Evaluation methodology aspects are relevant during the measurement of scientific output. Therefore additionally was searched, but not found a concept of avoiding gender bias in evaluation processes generally. Literature is focused mainly to gender mainstreaming needs (public policy concepts, organizational strategies) out of evaluations of whole research institutions.

Based on these findings were derived or developed indications with regard to the measuring and evaluation of scientific output at the individual level as the ACUMEN subject. The main results are as follows and were well accepted from the ACUMEN researchers group:

\section{Research concept}

ACUMEN research concept is an overall concept concerning both genders. In general it uses the same categories/categorization for male and female scientists, if they have equal attributes. At the same time the ACUMEN concept implies, that it may be important to have information specific for male and for female scientists, because of social or context dependencies.

The ACUMEN project design answers in negative to presumptions that determined human behavior patterns, qualities or attributes are linked to only one of the sexes (reification of gender stereotypes). This basic conceptual approach requires that all work packages will take into consideration possible different findings for male and female researchers and search for answers or further research questions about reasons for differences found.

\section{Research design/research questions}

The standard that both sexes are represented adequately is targeted by the defined properties of the ACUMEN data set. At the same time it is a standard to use the same research perspective and research methods for both sexes.

The main aspect in research design is to ask the same question about men and women in the sense that it is possible to get valid information about both sexes. So one should avoid seeing universally one sex as the active and the other one as the passive within a research question. In such a case it should be explored, for example, the passive role of men and the active role of women.

Of course it is necessary to formulate additionally a specific question for one sex only if there are not equal conditions for both sexes. So in two work packages will be monitored if identified phenomena in peer reviewing or web presence concern both sexes in the same way or if they are more typical for women and men. In the last case it would be important to improve if different framework situations of female and male scientists are the reason for identified differences or not and to ask questions about these reasons if necessary to come to an appropriate interpretation. In every case it is necessary to make it clear if a question relates to both sexes or only to one sex.

It could be interesting in ACUMEN to know more about the input of single team members into the scientific output of the different team members. One the one hand this is a general question of measuring output on an individual level in the ACUMEN project. On the other hand it could be necessary to learn some more about the question if there are equalities or differences between female and male scientists' inputs (kind, amount, quality) and to take this into account during measurement and interpretation of individual performance (as indirect output) too. So, for example, one work package deals with the question of "visible and invisible work in the current peer review and evaluation systems «.

Within processes of measurement of research outputs at individual level it can be recommended to ask men and women questions about their access to necessary 
or helpful resources, like mentoring, time, assistance to become a member of networks, finances, relevant information and so on. This data might be different for different career levels, disciplines and for the sexes. This is linked with the interesting question about the connection between the level of output and the efficiency of output.

\section{Methods and data collection}

It is not suitable to define one sex as the standard for the other sex and thereby define questions that limit the spectrum of the possible answers. It is essential to formulate each question in such a way that the theoretical possible range is seized by answers. E. g. a question should not be, if women work as efficiently as man. It would be better to ask about the work style and to find out if there really are different styles and if one is more effective. To avoid the so called "paradox gynozentrism «, too - one should not use research questions that exclude men in areas which are usually regarded as particularly important for women. It is suitable to extend the research question in such a way that also the role of the men is considered. So it seems to be important to respect during evaluation of individual research output that people's life cycle consists of different phases and scientists with (little) children have to share their time between family and job in a special way. There would be given some good starting points with the ACUMEN data set of scientists with different ages.

Of course, it is necessary during the collection of data to differentiate between founded facts and opinions heard as answers from asked female scientists about male scientists and vice versa. By using coding procedures one has to take care that identical procedures of coding are used for female and male scientists. Procedures of coding mean to subsume empirical findings in categories or to subsume codings to theoretical models or core variables. One should take care that codings with the same meaning not are worded actively for men but passively for women.

\section{Data analysis and interpretation}

Sex disaggregated data of all analyzed facts, groups and subgroups are the systematic basis to avoid gender bias during data interpretation.

During the interpretation one should take care to avoid overgeneralization of conclusions found for men or for women only, but to specify the conclusion to the relevant sex. Important is a precise description without any accusation. Furthermore, data should not be interpreted using one sex as the norm. So sometimes it is helpful to take over the view having women as norm to detect incorrect standardizations with men as the norm. Of course within the interpretation of information out of interviews answers of women and men have to be treated equally.

To make it sure that equal facts and results for men and women are not rated or interpreted in a different way without a real reason, one can reflect his results to find out if there are possibly preconceptions or stereotypes about rules, performance or reactions of each of the sexes. For instance, the exploration of web data done in ACUMEN will probably lead to different data for men and women scientists. For the interpretation, it is necessary to have reliable knowledge about the user behavior, user habits and preferences. During the interpretation it should be taken into account that - although gender roles and gender identities have evolved historically and are socially important - they are not necessary, not natural and not preferable. So it could be helpful to ask in interviews men and women from the different actors groups about their experiences with hindering effects out of gender roles (actual or expected).

It was shown that some situations or ongoings may have different implications for women and men. Often women have other self-esteem and self-concept or a higher level of self-criticism, which has to be taken into account. This may be relevant for the realization and interpretation of interviews planned in ACUMEN just like for the measurement of outputs of male and female scientists in general.

Title, abstract, diction and visualization of reports Naturally the methodical concept to avoid gender bias of data, findings and conclusions has consequences for title, abstract, diction and figures of publications and presentations too. So it is important to use verbalizations without gender bias, even under the restriction of very limited number of words. It would be useful for literature research to know from the title, abstract and key words if the subject was analyzed or with any sensibility to gender differences.

Male and female researchers should be pictured fittingly (also in the corresponding figures and tables, of course), regarding their relevance for the research subject. So should be proved, if continuously one sex is named before the other one if in sentences both are 
named. In statements and evidences about only one sex this should be pointed out clearly. It should be checked if the grammatical treatment regarding the active or passive verb form is equal for both sexes. (»Male scientists make career «, »Female Scientists are supported to make career.«). If ACUMEN work packages lead to new knowledge about women researchers' output or careers this should be clearly named and discussed in perception with (inappropriate) gender clichés. It is important not to reproduce gender clichés uncritically. For example, work life balance is not a question for women only.

\section{First application of the adapted concept}

In the ACUMEN project surveys and semistructured interviews are important methods to get more information about the implikations of peer review decisions of research funding organizations (of the European Research Council or in selected countries) or e.g. to identify how researchers are using the web to promote their scientific career and to disseminate their scientific advances. By using the adapted concept were deduced model questions for surveys and interviews, which are prepared by project partners, like for example:

- Do all members in your team/institution have equal access to resources necessary or helpful to create scientific output, like mentoring, time, assistance to get member of networks, finances, relevant information and so on? Do you see any dependencies to different career levels or to researcher's sex?

- How do you access your own input supporting the scientific output of your team colleagues?. How do you access the input given by your team colleagues supporting your own scientific output? Do you feel that these inputs should be taken into account in the measurement of the individual performance?

- Do you have own experiences or knowledge about experiences with hindering effects to create scientific outputs? Do you see any connection to gender roles?

\section{Resume}

By a two step approach it was possible to adapt an analytical concept developed for health care research to another research subject - the measuring and evaluation of scientific output at the individual level. To avoid systematic distortion effects during investigations in this subject one has to pay attention to possible risks during profiling of research questions, selection of subjects and methods, interpretation of results and verbalization. The adapted concept shows once more that the problem of gender bias has more than one dimension and thereby cannot be handled only by one method or action in a research process.

The results have some influence in the present ACUMEN literature review about the implications of different forms of gender bias for women's research careers and they will be refined by future findings out of the ACUMEN project.

\section{Acknowledgement}

This work is financed by the European Commission, SIS2010-1.3.3.1. Project full title: »Academic Careers Understood through Measurement and Norms«, project acronym: ACUMEN.

\section{Endnotes}

[1] Named as "paradoxial gynocentrism « - for instance if studies about single parents ignore single fathers.

\section{Bibliography}

Abbuhl, S. et al. (2010): Examining Faculty Awards for Gender Equity and Evolving Values. Journal of General Internal Medicine 25(1), 57-60.

ACUMEN (2011): http://research-acumen.eu/, cited: 21.07.2011.

Baer, S., Enders-Dragässer, U., Kuhl, M., Kreß, B., Sellach, B. (2003): Gender Bias - ein zentrales analytisches Konzept. Frankfurt am Main und Berlin: Wissensnetz Gender Mainstreaming für die Bundesverwaltung, 104-108, http://www.gender-mainstreaming. net/RedaktionBMFSFJ/ RedaktionGM/Pdf-Anlagen/wissensnetz-k omplettfassung,property=pdf,bereich $=$ gm,rwb=true.pdf, cited: 06.04.2011.

Bakken, L.L., Byars-Winston, A. et al. (2006): Viewing clinical research career development through the lens of social cognitive career theory. Advances in Health Sciences Education 11(1), 91-110.

Bird Sharon, R. (2011): Unsettling Universities' Incongruous, Gendered Bureaucratic Structures: A Case-study Approach. GENDER WORK AND ORGANIZATION 18(2), 202-230.

Duberley, J., Cohen, L. (2010): Gendering career capital: An investigation of scientific careers. Journal of Vocational Behavior 76(2), 187-197.

Eichler, M., Burke, M.A. (2006): The BIAS FREE Framework. A New Analytical Tool for Global Health Research. CANADIAN JOURNAL OF PUBLIC HEALTH 97 (1), 63-68. 
Eichler, M., Gustafson, D. L., Pompetzki, M. (1999): Moving toward equality: Recognizing and eliminating gender bias in health. Ottawa: Health Canada. In: Gustafson, D. L. (1999): Toward Inclusionary Practices in the Education of Nurses: A Critique of Transcultural Nursing Theory. The Alberta Journal of Educational Research 45 (4), 468-470.

Elg, U., Jonnergard, K. (2010): Included or excluded? The dual influences of the organisational field and organisational practices on new female academics. Gender and Education 22(2), 209-225.

European Commission (2009): Directorate-General for research, Directorate L - Science, Economy and Society. 2009. Statistics and Indicators on Gender Equality in Science.

Fuchs, J., Maschewsky, K., Maschewsky-Schneider, U. (2002): Zu mehr Gleichberechtigung zwischen den Geschlechtern: Erkennen und Vermeiden von Gender Bias in der Gesundheitsforschung. Blaue Reihe Berliner Zentrum Public Health 2002/04, 31ff. (as the translated Version of the never published original version: Eichler, M., Gustafson, D., Pompetzki, M. (1999): Moving Toward Equality: Improving the Health of Canada's People, Recognising and Eliminating Gender Bias. In: Health. Health Canada's training guide on gender equality. For Health Canada, http://biasfree.org/ history.html, cited: 01.07.2011).

Girves, J. E., Zepeda, Y. et al. (2005): Mentoring in a post-affirmative action world. Journal of Social Issues 61(3), 449-479.

Mayer, A. P., Files J. A. et al. (2009): The Academic Quilting Bee. Journal of General Internal Medicine 24(3), 427-429.

Morahan, P. S., Rosen, S. E. et al. (2011), The Leadership Continuum: A Framework for Organizational and Individual Assessment Relative to the Advancement of Women Physicians and Scientists. Journal of Womens Health 20(3), 387-396.

Morrissey, C. S., Schmidt, M. L. (2008): Fixing the System, Not the Women: An Innovative Approach to Faculty Advancement. Journal of Womens Health 17(8), 1399-1408.

Ruiz, T. M., Verbrugge, L. M. (1997): A Two Way View of Gender Bias in Medicine. Journal of Epidemiology \& Community Health 51 (2), 106-109, from http://www.springerlink.com/content/ 7t535r0v20512k15/, cited: 09.03.2011.

Risberg, G., Johansson, E. E., Hamberg, K. (2009): A theoretical model for analysing gender bias in medicine. International Journal for Equity in Health 8, 8.

Rose, G. L. (2005): Group differences in graduate students' concepts of the ideal mentor. Research in Higher Education 46(1), 53-80.

Winslow, S. (2010): Gender inequality and time allocations among academic faculty. Gender \& Society 24(6), 769-793.

\section{Authors}

\section{Dr. Ulla Große}

Forschungsgruppe »Innovations- und Regionalforschung Technische Hochschule Wildau [FH]

$\mathrm{T}+493375$ 508-513

ulla.grosse@th-wildau.de

\section{Dr. Martina Brandt}

Forschungsgruppe »Innovations- und Regionalforschung « Technische Hochschule Wildau [FH]

$\mathrm{T}+493375$ 508-512

martina.brandt@th-wildau.de 